\title{
LEGISLAÇÃO BRASILEIRA SOBRE GARANTIAS PARA AS CONCESSÕES
}

\author{
EURICO DE ANDRADE AZEVEDO*
}

1. O Problema Legal - 2. Por que a aplicação subsidiária da Lei 8.666/93? - 3. A Interpretação Literal - 4. A Lógica do Sistema - 5. A Lógica do Razoável - 6. Fins Sociais da Lei e exigências do bem comum

\section{O Problema Legal}

Tema que tem sido objeto de inúmeras discussões é o que diz respeito aos limites das garantias exigidas dos licitantes nas concorrências para a outorga de concessões de serviços públicos. $O$ problema concreto surgiu com o primeiro edital de licitação da concessão do complexo rodoviário Anhangüera - Bandeirantes. $O$ edital publicado pelo DER exigia quatro garantias distintas: garantia de execução das obras; garantia do pagamento da concessão (já que se trata de concessão remunerada); garantia de integralização do capital da empresa a ser constituída (SPC); e garantia para as funções de conservação e ampliação (a ser prestada por terceiros contratados e repassada ao concedente). Somadas umas às outras, ultrapassavam o limite de $10 \%$ (dez por cento) previsto no $\S 3^{\circ}$ do art. 56, da Lei Geral de Licitações e Contratos.

Embora não tenha havido impugnação de nenhuma concorrente, houve reclamação ao Tribunal de Contas do Estado que, depois de acurados debates, concluiu pela ilegalidade do edital por violação do citado dispositivo legal. Houve pedido de reconsideração por parte do DER, julgado improcedente por aquela egrégia Corte.

O problema que se coloca é o da aplicação subsidiária da Lei Geral das Licitações aos contratos de concessão de serviço público. A Lei 8.987/95, que regula a outorga de concessões de serviços e obras públicas, não impõe limites às garantias exigidas pelo poder concedente ao concessionário; estes limites decorreriam da

* Advogado em São Paulo, especialista em Direito Administrativo, sócio do escritório ANDRADE AZEVEDO e ALENCAR Consultoria Jurídica. 
aplicação do art. 56 e parágrafos da Lei $8.666 / 93$ que restringe essa garantia a 5\% (cinco por cento) do valor do contrato, podendo chegar a $10 \%$ (dez por cento) nas contratações de grande vulto e alta complexidade técnica.

\section{Por que a aplicação subsidiária da Lei 8.666/93?}

O sistema jurídico brasileiro apoia-se numa hierarquia rígida de normas formais escritas: a partir da Constituição Federal - que distribui as competências entre a União, os Estados e os Municípios - a eficácia normativa vai se efetivando por meio das leis complementares, leis ordinárias, decretos e outras normas de menor alcance. Pois bem, pela Constituição Federal, cabe à União legislar sobre normas gerais de licitação e contratação, em todas as modalidades, nas diversas esferas de governo (art. 22, XXVII). Estas normas vieram a se concretizar na Lei 8.666 , de 21.6.93, com as posteriores alterações introduzidas pela Lei 8.883, de 8.6.94.

Ao mesmo tempo, ao cuidar da ordem econômica e financeira, a Constituição dispõe, no art. 175:

"Art. 175 - Incumbe ao Poder Público, na forma da lei, diretamente ou sob regime de concessão ou permissão, sempre através de licitação, a prestação de serviços públicos.

Parágrafo único - A lei disporá sobre:

$I$ - o regime das empresas concessionárias e permissionárias de serviços públicos, a caráter especial de seu contrato e de sua prorrogação, bem como as condições de caducidade, fiscalização e rescisão da concessão ou permissão;

II - o direito dos usuários;

III - política tarifária;

IV - a obrigação de manter serviço adequado."

Com base nesse dispositivo, foi editada a Lei 8.987, de 14.2.95, que traçou as normas básicas do instituto da concessão. $\mathrm{E}$ aqui começam as dificuldades de interpretação.

A primeira lei - a Lei Geral de Licitações e Contratos -, que é anterior à Lei de Concessões, já estabelecia no art. 124: "aplicam-se às licitações e contratos para permissão e concessão de serviços públicos os dispositivos desta lei que não conflitem com a legislação específica sobre o assunto".

Anote-se: aplicam-se os dispositivos que não conflitem com a legislação especial.

De sua parte, a Lei de Concessões, ao cuidar da licitação necessária para a outorga da concessão, no art. 18 , determina que o edital da concorrência para chamamento geral dos interessados seja elaborado pelo poder concedente, "observados, no que couber, os critérios e as normas gerais da legislação própria sobre licitações e contratos".

E toda vez que uma norma legal faz remissão à outra, para mandar aplicá-la "no que couber", a única certeza que se tem é de que jamais haverá consenso entre os administradores e entre os juristas sobre "o que cabe" e "o que não cabe". 
Em outras palavras, a Lei de Concessões determina que o Poder Concedente exija do concessionário garantias para o exato cumprimento do contrato, inclusive as relacionadas com as futuras necessidades de expansão do serviço e consequiente modernização, aperfeiçoamento e ampliação dos equipamentos e instalações (art. $23, \mathrm{~V})$. Ao mesmo tempo, silencia quanto aos limites dessas garantias.

A Lei Geral de Licitações especifica as modalidades de garantia (caução em dinheiro ou títulos da dívida pública, seguro-garantia e fiança bancária); deixa a critério da autoridade competente exigir ou não a garantia; e limita o seu quantum a $5 \%$ do valor do contrato, podendo chegar a $10 \%$ para as obras, serviços e fornecimentos de grande vulto e alta complexidade técnica (art. 56 e parágrafos).

Pergunta: aplicam-se às concessões os limites estabelecidos na Lei de Licitações? É cabível (cabe ou não cabe?) a limitação imposta pela Lei Geral à lei especial das concessões?

O problema é de suma importância, pois as concessões, em geral, constituem contratos de longo prazo, que envolvem investimentos de vulto e que, sobretudo, põem em risco a responsabilidade do Poder Público pela prestação do serviço, geralmente de caráter essencial para os usuários.

\section{A Interpretação Literal}

Uma interpretação simplesmente gramatical nos levaria a dizer que as limitações impostas às garantias, pela Lei 8.666/93, são aplicáveis às concessões. Realmente, se a Lei $8.987 / 95$ é omissa a respeito de tais limites, pode-se dizer que os preceitos da outra norma são cabíveis.

Ocorre que a interpretação gramatical não pode ser aplicada isoladamente. É a primeira análise que se faz, mas há de estar vinculada a todo o sistema.

Interpretar é descobrir o sentido e o alcance da norma, procurando o seu significado dentro do sistema jurídico. Por isso mesmo, a interpretação literal há de estar jungida à interpretação sistemática, que busca a melhor significação da norma dentro do sistema jurídico em que ela se encerra, tendo em vista os seus objetivos e a solução de casos concretos. ${ }^{1}$

\section{A Lógica do Sistema}

A concessão é um contrato especial, que não se confunde com os contratos regulados pela Lei 8.666/93: obras, serviços e compras (fornecimentos). Estes são produtos de natureza instrumental, realizados por particulares para a Administração, para o exercício de suas atividades-meio. A concessão não. A concessão tem por objeto a transferência a um particular da prestação de um serviço público. Não é simplesmente a entrega de um produto à Administração, cessando a responsabilidade do contratado com o seu recebimento. $\mathrm{Na}$ concessão, o particular assume a prestação 
do serviço, por sua conta e risco, embora sob garantia contratual de um equilíbrio econômico-financeiro, remunerando-se pela própria exploração do serviço, através da tarifa cobrada dos usuários.

Por isso mesmo, não se pode dar à concessão o mesmo tratamento que se dá aos demais contratos administrativos de obras, serviços e compras. A concessão sempre mereceu referência especial nas últimas Constituições. E o atual art. 175 menciona expressamente o caráter especial do seu contrato.

Portanto, não é possível aplicar, subsidiariamente, a Lei 8.666/93 aos contratos de concessão toda vez que a Lei especial for omissa a respeito. É preciso verificar, primeiro se o dispositivo aplicável é compatível com as características do instituto, com o caráter especial do seu contrato.

Vejamos alguns exemplos:

- o prazo: a Lei 8.987/95 é omisssa a respeito do prazo contratual da concessão. Dever-se-iam aplicar os prazos previstos na Lei 8.666/93?

- os casos de dispensa de licitação: a Lei 8.987/95 também é omissa a respeito. Seriam aplicáveis todos os casos da Lei 8.666/93?

- da mesma forma, os preceitos referentes às garantias, previstos na Lei $8.666 / 93$, não podem ser transpostos para o contrato de concessão, porque não se ajustam às peculiaridade desse instituto.

- ao contrário, a audiência pública também não é contemplada na Lei 8.987/95, mas é perfeitamente aceitável a sua realização, já que se destina a ampliar o conhecimento da comunidade sobre a matéria.

É preciso respeitar a lógica do sistema jurídico. E esta lógica evidencia que os limites de 5 e $10 \%$ do valor do contrato, constantes do art. 56 da Lei 8.666/93, não se compadecem com a formidável responsabilidade que o Poder Público assume ao transferir para o particular a prestação de um serviço público - pelo qual ele continuará obrigado.

No caso, nem se pode dizer que a Lei de Concessões seja omissa, pois ela determina expressamente que o contrato deva consignar, necessariamente, "as garantias e obrigações do poder concedente e da concessionária, inclusive os relacionados às previsíveis necessidades de futura alteração e expansão do serviço e conseqüente modernização, aperfeiçoamento e ampliação dos equipamentos e das instalações" (art. 23, V).

Ora, como conciliar tais exigências, num contrato de duração de 20 ou 30 anos, com a garantia de $10 \%$ do valor ajustado?

\section{A Lógica do Razoável}

Há quarenta anos atrás, um notável filósofo mexicano - LUIS RECASÉNS SICHES - propugnava por uma nova filosofia de interpretação do direito: a lógica do razoável. Criticava severamente aqueles que tratam como abstratas realidades que são concretas. Não se pode dizer simplesmente - como neste caso: na omissão da Lei 8.987/95, aplica-se a Lei 8.666/93. "Não se pode tratar como teorema o que 
deve ser tratado como instrumento para a ação prática."2 Para ele, o alcance e a validade de um artigo de lei devem medir-se única e exclusivamente em função dos efeitos que produzem na vida real. E essa limitação de garantia a $10 \%$ do valor do ajuste, prevista para a generalidade dos contratos, transposta para a concessão, representa um verdadeiro desastre. Não é razoável.

E o princípio da razoabilidade - que está inscrito na Constituição de São Paulo como um dos princípios da Administração (art. 111) - serve para arredar os temores daqueles que acham que a inexistência de limites às exigências de garantias poderá levar a Administração a fazê-las arbitrariamente, afastando eventuais concorrentes. Está claro que só será legítima a exigência razoável de garantia, ditada pela proporção entre os riscos, o valor e a duração do contrato. Caberá ao administrador, diante do caso concreto, selecionar, entre aquilo que a lei permite genericamente, $o$ que for efetivamente mais adequado para o caso específico.

A esse propósito, o SUPREMO TRIBUNAL FEDERAL tem aplicado o princípio da razoabialidade em tema diferente, mas que pode ser chamado para comparação. A Constituição Federal proíbe qualquer discriminação, para admissão no serviço público ou privado, por motivo de idade, de sexo ou de estado civil. Não obstante, a E. CORTE tem admitido restrições, desde que sejam razoáveis em face da natureza e das atribuições do cargo a preencher (RT 717/301, relator: Min. MOREIRA ALVES).

\section{Fins Sociais da Lei e exigências do bem comum}

Uma outra regra que infelizmente tem sido esquecida, mas que é de suma importância, é a que consta do art. $5^{\circ}$ da Lei de Introdução ao Código Civil:

"Art. $5^{Q}$ - Na aplicação da lei, o juiz atenderá aos fins sociais a que ela se dirige e às exigências do bem comum."

A Lei de Introdução ao Código Civil, na verdade, não é uma lei introdutória ao Código Civil; vai muito além, contendo princípios gerais sobre todas as normas relativas ao direito privado e ao direito público. Portanto, seus preceitos abrangem também o direito administrativo.

Ora, na interpretação da lei, há de se indagar dos fins a que ela se destina e das exigências do bem comum. Assim deve ser feito com relação à Lei Geral de Licitações e à Lei de Concessões.

Nós estamos reaprendendo a trabalhar com o instituto jurídico das concessões. Depois de muito utilizadas na primeira metade deste século (embora sem legislação específica), foi sendo abandonada com a assunção pelo Estado da prestação dos serviços públicos, principalmente através das empresas por ele criadas para esse fim. É evidente que, nesses casos, não havia necessidade de garantias, pois era o próprio Estado quem assumia todos os riscos. Já o mesmo não ocorre agora, quando a 
execução do serviço é transferida ao particular, mas a responsabilidade última pelo atendimento dos usuários é do Poder Público.

Justifica-se, portanto, que o Poder Concedente cerque-se de todas as garantias necessárias para assegurar a prestação do serviço adequado, maiormente quando cada garantia tem uma finalidade precípua e diversa da outra, como no caso da Rodovia Anhangüera - Bandeirantes.

Ora, a Lei de Concessões foi editada precisamente para possibilitar ao Estado despojar-se da execução de tarefas que melhor podem ser realizadas pelo setor privado, com reativação de investimentos na infra-estrutura, cabendo ao Poder Público, como missão irrevogável e fundamental, a regulamentação e a fiscalização dos serviços, representando e defendendo os usuários e os interesses da sociedade ${ }^{3}$.

O fim social da Lei de Concessões, portanto, é ampliar o leque de concessões pelo Estado, ao mesmo tempo em que assegura a este o controle e as garantias indispensáveis à boa prestação do serviço, o que é incompatível com a aplicação do limite de $10 \%$ sobre o valor do contrato!

Bem comum é o bein-estar social, o bem do povo em geral, expresso sob todas as formas de satisfação das necessidades comunitárias. Nele se incluem as exigências materiais e espirituais dos indivíduos coletivamente considerados. ${ }^{4}$ No caso do direito administrativo, o bem comum se confunde com o interesse público. Realmente, o que é o interesse público senão o bem de toda a coletividade? Ora, no exame do capítulo das garantias a serem exigidas para a outorga de concessão, o interesse público não está na imposição de um limite máximo de $10 \%$ do valor do contrato; está enin deixar ao prudente critério da autoridade a exigência de tais ou quais garantias, de acordo com o vulto das obras a serem executadas, as condições de operação do serviço, a duração do contrato, as necessidades dos usuários, à permanente modernização dos equipamentos e instalações etc. etc. Tudo isso, é claro, sempre dentro do princípio da razoabilidade, em função do qual só será lícita a exigéncia adequada ao fim a que se destina.

\section{Concessão de serviço precedida de obra pública}

Feitas estas considerações, convém lembrar que a Lei de Concessões, no parágrafo único do citado art. 23 - cláusulas essenciais do contrato - dispõe que, os contratos de concessão de serviço público precedido da execução de obra pública deverão, adicionalmente: I - estipular os cronogramas físico-financeiros de execução das obras vinculadas à concessão, e II - exigir garantia do fiel cumprimento, pela concessionária, das obrigações relativas às obras vinculadas à concessão.

Este dispositivo nos fornece a pista para a solução da controvérsia. Quando a concessão do serviço for precedida da execução de obra, correta será a aplicação do

3 FERNANDO HENRIQUE CARDOSO, prefácio ao livro de ARNOLDO WALD e outros, O Direito de Parceria e a Nova Lei de Concessōes, Ed. RT, 1996.

4 HELY LOPES MEIRELLES, Direito Administrativo Brasileiro, Malheiros Editores, $23^{2}$ ed., atualizada por Eurico de Andrade Azevedo e outros, 1998, p. 483. 
limite de $10 \%$ do valor da obra como exigência do cumprimento da obrigação. Isto porque esta parte do contrato de concessão - execução da obra - é semelhante ao contrato de obra pública, menos com relação à forma de pagamento. Por conseguinte, é razoável que, com relação ao valor da obra seja aplicável o limite previsto na Lei Geral de Licitações. Já no que diz respeito aos outros aspectos da concessão: garantia do pagamento da concessão, nas concessões remuneradas; garantia de integralização do capital da empresa a ser constituída, se for o caso; e garantia para as funções de conservação e ampliação do serviço, a limitação improcede.

Este entendimento permitirá que as Leis de Concessões e Licitações possam ser interpretadas de forma harmoniosa, que facilite e não dificulte o traspasse dos serviços públicos à iniciativa privada, única maneira de retomar os investimentos nos vários setores indispensáveis à melhoria do padrão de vida dos usuários, com as garantias indispensáveis à consecução do bem comum. 


\title{
A Origem do Direito de Solidariedade
}

\author{
José Fernando de Castro Farias
}

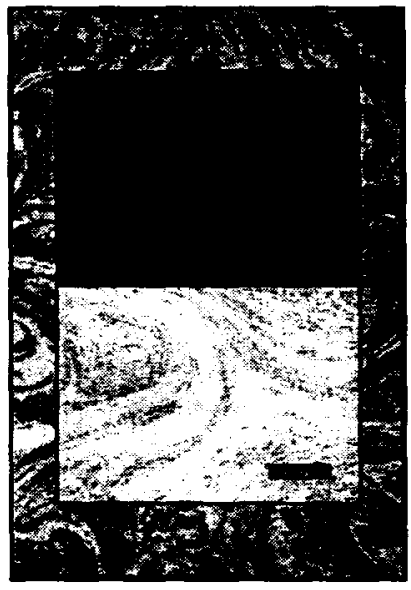

Este livro aborda temas centrais: a revolta contra o formalismo jurídico, direito e justiça, direito e experiência, os mecanismos jurídicos de gestão do social, o discurso solidarista, o paradigma da solidariedade e o solidarismo jurídico. Os enunciados do direito de solidariedade fazem parte de uma mesma formação discursiva, baseando-se em mecanismos comuns, cuja investigação passa por um estudo da História das Idéias Jurídicas, e, mais precisamente, por uma abordagem arqueológica do direito que remonta à Europa do fim do século XIX e do início do século $\mathrm{XX}$.

Ref. $0166 \quad$ Brochura 307 págs.

Form. 14x21 1998

\section{A Reconstrução dos Direitos Humanos da Tributação}

Nesta obra, o autor retorna à análise do fenômeno tributário, agora na vertente dos Direitos Humanos, a partir dos eventos que se seguiram à Revolução Francesa, elaborando uma inédita Teoria Geral da Tributação de profunda importância para a emancipação da Democracia.

Alberto Nogueira

Alberto Nogueira

Ref. 0143

Brochura

Form. 14x21

472 págs.

A RECONSTRUÇÃO DOS DIREITOS HUMANOS

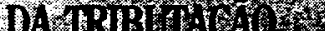

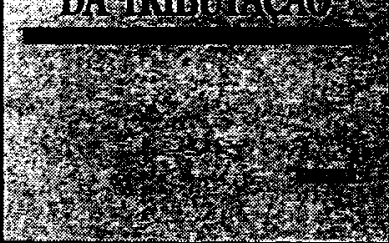

